\title{
Psychometric properties of the Iranian version of the Anxiety Sensitivity Index-3 (ASI-3)
}

\author{
Propriedades psicométricas da versão iraniana da \\ Anxiety Sensitivity Index-3 (ASI-3)
}

\author{
Ali Akbar Foroughi, ${ }^{1}$ Mohsen Mohammadpour, ${ }^{2}$ (D) Sajad Khanjani, ${ }^{3}$ Sahar Pouyanfard, ${ }^{2}$ \\ Nadia Dorouie, ${ }^{2}$ Ali Akbar Parvizi Fard ${ }^{1}$
}

\begin{abstract}
Introduction: Anxiety sensitivity plays a prominent role in the etiology of anxiety disorders. This construct has attracted widespread interest from experts and researchers. The Anxiety Sensitivity Index (ASI-3) is the most common scale for measuring anxiety sensitivity.

Objective: To analyze the psychometric properties and factor structure of the ASI-3 in Iranian student samples.

Methods: 220 students (135 women, 85 men) from Kermanshah University of Medical Sciences were selected by the convenience sampling method to evaluate the psychometric properties and analyze the factor structure of the ASI-3. The subjects were also asked to complete the Acceptance and Action QuestionnaireII (AAQ-II), Whiteley Index, Intolerance of Uncertainty, and Neuroticism scales. LISREL and SPSS were used to analyze the data. Cronbach's alpha and correlation coefficients were calculated and confirmatory factor analysis was conducted.

Results: The results of the confirmatory factor analysis revealed a three-factor structure with physical, cognitive, and social components (comparative fit index $=0.94$; normed fit index $=$ 0.91 ; root mean square error of approximation $=0.09$ ). The ASI3 had positive and significant correlations with health anxiety (0.59), intolerance of uncertainty (0.29), and neuroticism (0.51). Furthermore, the ASI-3 had a negative and significant correlation with the AAQII $(-0.58)$. Cronbach's alpha coefficients for the whole scale and for the physical, cognitive, and social concerns factors were $0.90,0.74,0.79$, and 0.78 , respectively. The invariance of the index was significant compared to the original English version.

Conclusion: In general, the results support the adequacy of the psychometric properties of the Persian version of the ASI-3. Theoretical and applied implications will be discussed.
\end{abstract}

Keywords: Validity and reliability, confirmatory factor analysis, Anxiety Sensitivity Index-3 (ASI-3).

\section{Resumo}

Introdução: A sensibilidade à ansiedade desempenha um papel proeminente na etiologia dos transtornos de ansiedade. Esse construto tem atraído grande interesse entre especialistas e pesquisadores. O Anxiety Sensitivity Index (ASI-3; em português, Escala de Sensibilidade à Ansiedade) é a medida mais utilizada para medir sensibilidade à ansiedade.

Objetivo: Analisar as propriedades psicométricas e a estrutura fatorial do ASI-3 em estudantes iranianos.

Métodos: Para avaliar as propriedades psicométricas e analisar a estrutura fatorial do ASI-3, 220 estudantes (135 mulheres, 85 homens) da Kermanshah University of Medical Sciences, Irã, foram selecionados via amostragem por conveniência. Eles foram solicitados a completar os seguintes instrumentos: Acceptance and Action Questionnaire-II (AAQ-II), Whiteley Index, Intolerance of Uncertainty e Neuroticism. Os programas LISREL e SPSS foram utilizados para analisar os dados. Alfa de Cronbach e coeficientes de correlação foram calculados, e foi realizada análise fatorial confirmatória.

Resultados: Os resultados da análise fatorial confirmatória revelaram uma estrutura de três fatores, incluindo componentes físicos, cognitivos e sociais [comparative fit index (CFI) $=0,94$; normed fit index $(\mathrm{NFI})=0,91$; root mean square error of approximation (RMSEA) $=0,09]$. O ASI-3 demonstrou correlações positivas e significativas com ansiedade em relação à saúde $(0,59)$, intolerância à incerteza $(0,29)$ e neuroticismo $(0,51)$. Além disso, o ASI-3 teve uma correlação negativa e significativa com o AAQII $(-0,58)$. O coeficiente alfa de Cronbach para toda a escala e para os fatores preocupação física, cognitiva e social foram $0,90,0,74,0,79$ e 0,78, respectivamente. A invariância do índice foi significativa em relação à versão original.

Conclusão: Em geral, os resultados sugerem que as propriedades psicométricas da versão persa do ASI-3 são adequadas. Implicações teóricas e práticas serão discutidas.

Descritores: Validade e confiabilidade, análise fatorial confirmatória, Anxiety Sensitivity Index-3 (ASI-3), Escala de Sensibilidade à Ansiedade.

\footnotetext{
${ }^{1}$ Department of Clinical Psychology, Kermanshah University of Medical Sciences, Kermanshah, Iran. ${ }^{2}$ Research Committee, Kermanshah University of Medical Sciences, Kermanshah, Iran. ${ }^{3}$ Department of Clinical Psychology, School of Behavioral Sciences and Mental Health, Tehran Psychiatric Institute, Iran University of Medical Sciences, Tehran, Iran.

Submitted Sep 26 2018, accepted for publication Jan 072019.

Suggested citation: Foroughi AA, Mohammadpour M, Khanjani S, Pouyanfard S, Dorouie N, Parvizi Fard AA. Psychometric properties of the Iranian version of the Anxiety Sensitivity Index-3 (ASI-3). Trends Psychiatry Psychother. 2019;41(3):254-261. http://dx.doi.org/10.1590/2237-6089-2018-0078
} 


\section{Introduction}

Anxiety sensitivity is defined as a fear of experiencing anxiety or physiological sensations associated with anxiety and the potential cognitive, physiological and social consequences of these experiences. ${ }^{1-4}$ Sensitivity to anxiety is a stable but flexible multi-dimensional personality trait. ${ }^{5,6}$ Sensitivity to anxiety plays an important role in the development and maintenance of anxiety disorders, especially panic disorder, ${ }^{7-9}$ and is a risk factor for mood disorders, suicide, ${ }^{8,10}$ and substance abuse. ${ }^{11}$ People with high anxiety sensitivity often react negatively to symptoms of anxiety, while people with low anxiety sensitivity, may experience these symptoms as unpleasant, but do not consider them as threatening. ${ }^{12}$

In recent years, research and theories on anxiety sensitivity have grown significantly, which has led to development and enhancement of various selfassessment scales for anxiety sensitivity evaluation. ${ }^{13}$ One of the most controversial subjects in the anxiety sensitivity literature is the factor structure of these measures. ${ }^{14}$ Between 1986 and 2009, the Anxiety Sensitivity Index (ASI) was the first and most extensive measure used to assess this construct. ${ }^{15}$ The first edition of the ASI was revised after being criticized for its psychometric properties. In 1998, Taylor and Cox proposed the Anxiety Sensitivity Index-Revised (ASI-R) as a broad scale for measuring anxiety sensitivity and its dimensions. This measure has a four-factor hierarchical structure, including 1) fear of respiratory symptoms; 2) fear of publicly observable anxiety reactions; 3) fear of cardiovascular symptoms; and 4) fear of cognitive dyscontrol. ${ }^{3}$ Due to the unstable factor structure of this scale, another correction was taken into account. The latest version of the Anxiety Sensitivity Index (ASI-3) was introduced by Taylor et al., in 2007. ${ }^{16}$

The ASI-3 is a multi-dimensional measure with 18 items characterized by three correlated sub-scales covering physical concerns (e.g., "It scares me when my heart beats rapidly"), cognitive concerns (e.g., "when I cannot keep my mind on a task I worry that I might be going crazy"), and social concerns (e.g., "it's important for me not to seem nervous"). ${ }^{16}$ Taylor et al. reported that the dimensions of anxiety sensitivity vary in patients with obsessive-compulsive, general anxiety, social anxiety, and panic disorders. For example physical concerns in panic patients, social concerns in social anxiety patients, and cognitive concerns in patients with generalized anxiety disorder and panic disorder all score higher. ${ }^{16}$

Taylor et al. ${ }^{16}$ showed that the ASI- 3 is characterized by a three-factor hierarchical structure (three subscales for the first level and one general AS for the second level) in each of the clinical and non-clinical samples. These results are repeated in mixed samples of students and patients with anxiety disorders. ${ }^{17}$ In various studies, the three-factor structure for anxiety sensitivity has been reported ${ }^{15,17-23}$ and the invariance of its internal structure has been shown in various countries. ${ }^{15,24}$ In contrast, Osman et al. ${ }^{25}$ and Ebesutani et al. ${ }^{13}$ conducted studies administering the ASI-3 to students and obtained a two-factor model.

Considering the discrepancies between some of the above-mentioned studies with relation to the ASI-3's factor structure and the superiority of the recent version of this questionnaire over the previous versions, the current study seeks to answer the following questions: Will the three-factor structure of the ASI-3 be confirmed? Does the ASI-3 have appropriate divergent and convergent validity?

\section{Method}

\section{Participants}

The present study was a descriptive, cross-sectional study. The statistical population included all students at the Kermanshah University of Medical Sciences during the 2017-2018 academic year. The recommended sample size for the confirmatory factor analysis is about 200 participants for ten factors. ${ }^{26,27}$ Accordingly, the 220 students (135 girls, 85 boys) were recruited from Kermanshah University of Medical Sciences, selected by the convenience sampling method.

\section{Measures}

Anxiety Sensitivity Index-3

This is a self-report measure containing 18 questions that assess the degree of people's fears of the negative consequences of symptoms and anxietyrelated feelings. (e.g., "It scares me when my heart beats rapidly"). The ASI-3 consists of a general factor and three sub-scales (physical, cognitive, and social concerns). Sentences are scored from 0 (very low) to 4 (very high). Sub-scales range from 0 to 24 and the total score is in the range of 0 to 72 . The ASI- 3 has good internal consistency (ranging from 0.76 to 0.86 for physical concerns, from 0.79 to 0.91 for cognitive concerns, and from 0.73 to 0.86 for social concerns), convergent validity and divergent validity. ${ }^{16}$

\section{Whiteley Index}

The Whiteley (Pilowsky) Index was designed in 1967 and is one of the most widely used measures for assessing the dimensions of health anxiety. Factor analysis of findings revealed three factors: physical 
preoccupation, fear of disease, belief in disease. ${ }^{28,29}$ However, subsequent studies showed inconsistent results in terms of the factor structure. ${ }^{30}$ There are two versions of the scale, each containing 14 items. One has a dichotomized response format of yes/no, while the other has a 5-point Likert scale response format (from $1=$ totally disagreeing to $5=$ completely agreeing). $\cdot^{30,31}$ Total scores range from 14 to 70 . The WI has shown good internal consistency, concurrent validity, and high test-retest reliability $(R=0.81)$ and can distinguish individuals with severe health anxiety from others. ${ }^{28,32}$ Cronbach's alpha in the current study was 0.70.

\section{Intolerance of Uncertainty Scale (Short Form)}

A 12-question measure used to assess individuals' ability to tolerate ambiguity, uncertainty consequences, perceived implications of uncertainty, and efforts towards controlling the future. ${ }^{33}$ The correlation coefficient of this scale was 0.96 with the original version of the Intolerance of Uncertainty Scale. ${ }^{34}$ It has a total score and two subscales (prospective subscale and inhibitory subscale). The prospective subscale evaluates the tolerance of uncertainty regarding the future, and the inhibitory subscale evaluates the person's interpretation of the uncertainty as paralyzing. The Cronbach's alpha coefficients are reported to be 0.85 for each of the two subscales and 0.91 for the whole scale. ${ }^{33}$ In a preliminary study of the psychometric properties of this scale in a sample of the Iranian student population, the Cronbach's alpha coefficients for internal consistency of the Prospective and Inhibitory sub-scales and the total score for intolerance of uncertainty were calculated as $0.87,0.84$, and 0.89 , respectively. ${ }^{35}$

\section{Neuroticism subscale of NEO Personality Inventory (NEO-FFI)}

The NEO-FFI inventory was created by Costa \& McCrae in 1989 and contains 60 items designed to measure five personality factors: neuroticism; extroversion; openness to experience (flexibility); agreeableness; and conscientiousness. The original version of this measure has good psychometric properties. ${ }^{36}$ The Iranian version of NEO-FFI has good reliability. In a study conducted by Mirzaei et al. in Iran, according to Cronbach's alpha the reliability of the neuroticism subscale of this measure was 0.88.37 Also, Anisi et al. obtained a neuroticism Cronbach's alpha coefficient of $0.80 .^{38}$

\section{Acceptance and Action Questionnaire-II (AAQ-II)}

The AAQ-II was developed by Bond et al. ${ }^{39}$ The AAQ-II has 10 items and assesses features such as acceptance, avoidance of experience, and psychological flexibility. Statements are evaluated on a seven-grade
Likert scale, from 1 (it does not apply to me at all) to 7 (it always applies to me). Higher scores indicate greater psychological flexibility. The mean alpha coefficient was 0.84 and 3 and 12-month re-test reliability were 0.81 and 0.79 respectively. ${ }^{39}$ Abasi et al. conducted a study that investigated the psychometric properties of the AAQ-II in Iran. The results of exploratory factor analysis revealed two factors: avoiding emotional experiences and control of life. Internal consistency and the questionnaire's harmonic coefficient were satisfactory in four groups. ${ }^{40}$

\section{Procedure}

Current guidelines, ${ }^{41,42}$ for cross-cultural adaptation of measures generally recommend a multi-step process, including forward and backward translations and steps to ensure the conceptual equivalence of the measures. In our translation and preparation of the ASI-3, we took the following steps:

1) Translation of the original version of the ASI-3 from English into Persian by a group of PhDs and professors of clinical psychology. Any differences were resolved by agreement.

2) Back-translation from Persian into English by another two mental health experts independently. The translated text was compared with the original text and its drawbacks were examined. Again, any differences were resolved by agreement.

3) Revision of the final translation by the first author.

4) A pilot study was conducted with a sample of 20 Persian students from Kermanshah University of Medical Sciences to examine whether they found the ASI-3 acceptable and understandable.

After completion of these procedures, the final scale was prepared for the sample. In this study, all subjects were completely at liberty to participate in the research and signed a free and informed consent form. In accordance with ethical considerations, before completing the questionnaire, the research objectives were explained to participants and they were assured that the information collected would be analyzed by group. In this study, the AAQ-II was used to determine divergent validity. The AAQ-II assesses the degree of experiential avoidance. Individuals who score lower on the AAQ-II are open to their inner experiences, unlike those who score higher on the ASI-3.43 The NEO-FFI, Intolerance of Uncertainty Scale, and Whiteley Index were used to test convergent validity. Research has shown that anxiety sensitivity and dysfunctional cognition about health may play a significant role in development and maintenance of health anxiety symptoms. ${ }^{44}$ Also, 
anxiety sensitivity and intolerance of uncertainty are important risk factors for cyberchondria. ${ }^{45}$

\section{Data analysis}

Data were cleaned and screened. Missing data were $5 \%$ of the data set. Thus, list-wise deletion with no imputation of data was used for the present analyses. The decision of whether to remove or retain outliers was taken after comparing the original mean with the $5 \%$ trimmed mean. Assumptions of normality were checked, and skew was not evident in the subscales or total scale score for the normative group. Confirmatory factor analysis was chosen to examine the ASI-3's suitability. This method offers a variety of statistical tests and indices designed to assess the 'goodnessof-fit' of the models identified. ${ }^{46}$ Construct validity of the ASI-3 was assessed using structural equations modeling (SEM) with a sample of 220 students from Kermanshah University of Medical Sciences. The three factors structure of the ASI-3 suggested for the original version was tested with LISREL 8.5. The Bartlett test and the Kaiser-Meyer-Olkin index were used to determine the adequacy of the sample. Multivariate analysis of variance (MANOVA) was employed to investigate gender-based difference between women and men for the three ASI-3 subscales (dependent variables) with gender used as an independent variable in the analysis. Box's M assumption of the homogeneity of variancecovariance matrices and the assumption normality were tested and confirmed in advance. Concurrent validity was investigated by examining Pearson correlations.
The internal consistency of the ASI-3 and its subscales was calculated using Cronbach's alpha coefficient. Data were analyzed using SPSS 18.

\section{Results}

In this study, the age range of all 220 (135 women, $61.4 \%$ and 85 men, $38.6 \%$ ) students was $18-27$, with mean and standard deviation of $22.22 \pm 2.30$. Table 1 shows the means and standard deviations for total anxiety sensitivity score and the three factors for women and men. No significant difference in total sensitivity to anxiety score was observed between men and women $\left(T_{218}=0.05, p=0.96\right)$. As shown in Table 1 , a MANOVA test was conducted to examine differences between men and women for the three factors. These results also indicated no significant difference between genders in the sub-scales of this index $(p<0.05)$. Table 2 shows correlations between ASI-3 factors and total score.

The results for divergent and convergent validity are presented in Table 3. As can be observed from the table, correlations between the anxiety sensitivity score and health anxiety $\left(r_{220}=0.59, p=0.001\right)$, intolerance of uncertainty $\left(r_{220}=0.29, p=0.001\right)$, and neuroticism $\left(r_{220}=0.50, p=0.001\right)$ are all positive and significant, which indicates that the convergent validity is appropriate. Furthermore, the ASI-3 has a negative and significant correlation with the AAQII $\left(r_{220}=-0.58, p=0.001\right)$, which indicates that the divergent validity is appropriate.

Table 1 - Comparison of anxiety sensitivity in women and men

\begin{tabular}{|c|c|c|c|c|c|c|}
\hline & \multicolumn{3}{|c|}{ Mean \pm standard deviation } & \multirow[b]{2}{*}{$\mathbf{F}$} & \multirow[b]{2}{*}{ df } & \multirow[b]{2}{*}{ Sig. } \\
\hline & Women & Men & Total & & & \\
\hline Anxiety sensitivity & $26.05 \pm 14.24$ & $25.95 \pm 10.98$ & $26.01 \pm 13.05$ & & & \\
\hline Physical concern & $8.67 \pm 4.95$ & $8.22 \pm 4.23$ & $8.50 \pm 4.68$ & 0.48 & 218 & 0.49 \\
\hline Cognitive concern & $7.51 \pm 6.48$ & $7.88 \pm 3.84$ & $7.66 \pm 5.60$ & 0.22 & 218 & 0.64 \\
\hline Social concern & $9.87 \pm 5.07$ & $9.84 \pm 4.67$ & $9.86 \pm 4.91$ & 0.01 & 218 & 0.98 \\
\hline
\end{tabular}

$\mathrm{df}=$ degrees of freedom.

Table 2 - Correlation coefficients for anxiety sensitivity and its factors

\begin{tabular}{lcccc}
\hline Variable & $\mathbf{1}$ & $\mathbf{2}$ & $\mathbf{3}$ & $\mathbf{4}$ \\
\hline Physical concern & - & $* 0.76$ & $* 0.68$ & $* 0.91$ \\
Cognitive concern & - & - & $* 0.67$ & $* 0.90$ \\
Social concern & - & - & - & $* 0.88$ \\
Anxiety sensitivity & - & - & - & - \\
\hline
\end{tabular}

$* \mathrm{p}=0.01$. 
Figure 1 shows the relationships between sensitivity to anxiety and its subscales and individual items. The Bartlett test returned a Chi-square value of $1,614.35$ and a significance level of 0.001 . The Kaiser-Meyer-Olkin index value was 0.90. These two results indicate the adequacy of the sample and are good indicators of the suitability of data for factor analysis. In total, $53.74 \%$ of total anxiety sensitivity variance is explained by the ASI-3. The results of fitting the model show that the hypothesized factor structure of ASI- 3 has a good fit: $x 2 / d f=2 / 99$; root mean square error of approximation (RMSEA) $=0.09$; incremental fit index $($ IFI $)=0.94 ;$ goodness of fit index $(\mathrm{GFI})=0.83$; normed fit index $(\mathrm{NFI})=0.91$; non-normed fit index $(N N F I)=0.93$; and comparative fit index $(\mathrm{CFI})=0.93$.

Reliability of the ASI-3 was assessed using Cronbach's alpha coefficients. Cronbach's alpha coefficients were $0.74,0.79$, and 0.78 for physical, cognitive, and social concerns respectively. On the other hand, the total ASI-3 score has a coefficient of 0.90 which indicates the ASI-3 has appropriate internal consistency.

Table 3 - Correlation between ASI, health anxiety, intolerance of uncertainty, neuroticism and AAQ-II

\begin{tabular}{|c|c|c|c|c|c|}
\hline Variable & 1 & 2 & 3 & 4 & 5 \\
\hline 1. Sensitivity to anxiety & - & $* 0.59$ & $* 0.29$ & $* 0.50$ & $*-0.58$ \\
\hline 2. Health anxiety & - & - & $* 0.21$ & $* 0.35$ & $*-0.56$ \\
\hline 3. Intolerance of uncertainty & - & - & - & $* 0.24$ & $*-0.38$ \\
\hline 4. Neuroticism & - & - & - & - & $*-0.45$ \\
\hline 5. AAQ-II & - & - & - & - & - \\
\hline
\end{tabular}

AAQ-II = Acceptance and Action Questionnaire-II.

$* \mathrm{p}=0.01$.

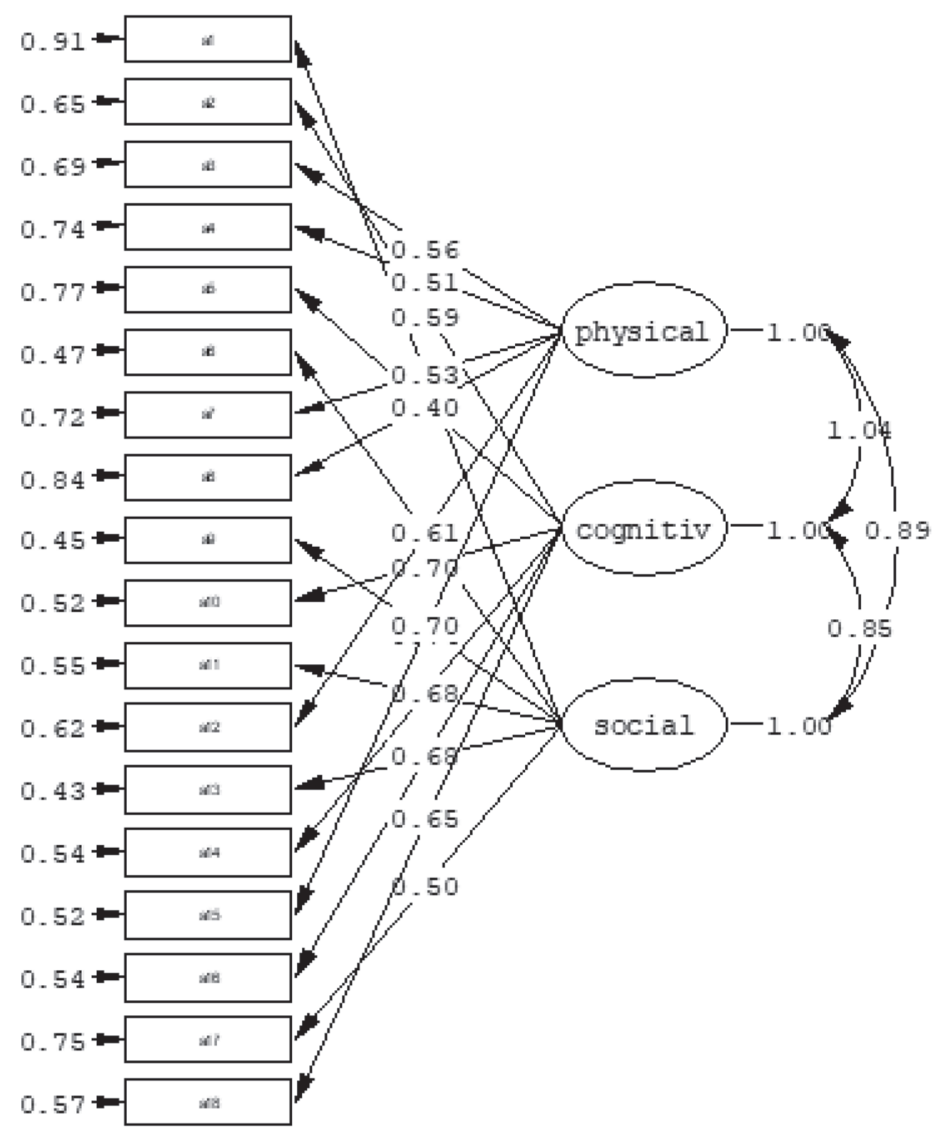

Figure 1 - Confirmatory factor analysis for the ASI. 


\section{Discussion}

The purpose of this study was to assess the psychometric properties of the Iranian version of the ASI-3. The results showed that the three-factor structure of this scale had an acceptable fit. After performing factor analysis, 3 factors of physical, cognitive, and social concerns were extracted from the total scale, which explained $53.74 \%$ of the total variance of sensitivity to anxiety. These findings are consistent with the findings of Taylor et al., Lim \& Kim, Wheaton et al., Kemper et al., and Petrocchi et al. 16,17,21,22,47 In those studies, three sub-scales and a general factor were obtained. Studies have shown that each factor is associated with different constructs. Physical concerns are strongly associated with panic disorder, agoraphobia, health anxiety, and somatization. ${ }^{16,17,19,22,25,48}$ On the other hand, social concerns are correlated with fear of negative evaluation, introversion, and social anxiety, ${ }^{15,16,22,48,49}$ but inconclusive findings have been reported in relation to cognitive concerns. Some studies did not find a specific relationship between cognitive concerns and anxiety disorders, but they did seem to be more associated with general distress and depression, 3,49,50 while other studies have concluded that cognitive concerns are associated with generalized anxiety disorder and posttraumatic stress disorder. ${ }^{17,48}$

The results of analysis of gender differences in the ASI -3 total score and subscales were not statistically significant. These findings were consistent with Taylor et al., Escocard et al., Osman et al., and Wheaton et al., showing that anxiety sensitivity was not affected by age, education, or gender. ${ }^{16,17,19,25}$ In contrast, the results are not consistent with a study by Sandin et al., in which women had higher anxiety sensitivity than men. ${ }^{18}$ Additionally, the cross-cultural invariance of the three-factor hierarchal structure has been confirmed by factor analysis of samples from different communities as well as in patients with anxiety and mood disorders from South America, Europe, the Middle East, and Asia. ${ }^{15,18-22}$ These findings support the idea that anxiety sensitivity is not sensitive to most socio-demographic variables.

The ASI-3 also had good internal consistency. Cronbach's alpha coefficient was $0.74,0.79,0.78$, and 0.90 for physical, cognitive, social, and total indicators, respectively. These findings are also consistent with the findings of the study by Taylor et al., which reported internal consistency ratings in the range of 0.80 to 0.90 for the sub-scales and 93.9 for the total score. ${ }^{16}$ It is also congruent with the study by Wheaton et al., whose internal consistency was between 0.80 and 0.90 for sub-scales and 0.93 for the total index score, and a study by Rifkin et al., where internal consistency was 0.83 to 0.89 for sub-scales and 0.91 for the total index score. ${ }^{17,50}$ These coefficients represent good consistency for this indicator. Additionally, in the present study, the three sub-scales were highly correlated with total anxiety sensitivity score (ranging from 0.88 to 0.91 ) and were related to each other intermediately and strongly (ranging from 0.67 to 0.76 ). These results are consistent with studies by Sandin et al. and by Lim and Kim. ${ }^{18,21}$

Earlier studies with the original versions of anxiety sensitivity have suggested that anxiety sensitivity is associated with a range of psychopathological symptoms. ${ }^{51}$ Therefore, the Whitley Index, the Intolerance of Uncertainty Scale, and the Neuroticism Scale were used to calculate the convergence validity of the ASI-3. The analyses showed that anxiety sensitivity has positive and significant correlations with all of these measures. These findings are consistent with a meta-analysis by Kristin Naragon-Gainey, who found a large effect size for the relationship between anxiety sensitivity and psychopathology, ${ }^{52}$ and also with other studies that showed that anxiety sensitivity is positively correlated with health anxiety, intolerance of uncertainty, and neuroticism.8,17,53-56 Anxiety sensitivity had the highest correlation with health anxiety and the lowest correlation with intolerance of uncertainty. This finding is consistent with Wheaton et al., who indicated that anxiety sensitivity, especially physical anxiety, is strongly correlated with health anxiety in clinical and non-clinical samples. ${ }^{17,54}$ To explain these findings, it can be stated that anxiety sensitivity is a risk factor for health anxiety in cognitive-behavioral models. The fear of arousal-related sensations causes people to mistakenly believe that harmless symptoms or sensations are signs of a medical problem that leads to health anxiety. ${ }^{57}$ Additionally, O'Bryan et al. showed that intolerance of uncertainty indirectly affects health anxiety through the physical concerns, which indicates that anxiety sensitivity and intolerance of uncertainty are independent structures, although they are related to each other. ${ }^{33,56}$ The AAQ-II was used to calculate the divergent validity of the ASI-3 in the present study. The results showed that anxiety sensitivity has a negative and significant correlation with the AAQ. These findings are consistent with studies by Esteve, Ramírez-Maestre, López-Martínez, ${ }^{58}$ and Kämpfe et al. ${ }^{59}$ In these studies, a negative and significant relationship was found between anxiety sensitivity and acceptance. Hayes suggests that acceptance involves "experiencing events fully and without defense, as they are" 43 Whereas, people with high sensitivity to anxiety believe that their physical sensations will have negative somatic, cognitive, or social consequences. 
In general, the results of this study showed that the Iranian version of the ASI-3 has acceptable psychometric properties in the student community and has high consistency and convergent and divergent validity. Anxiety sensitivity plays an important role in most of the emotional disorders, such as panic disorder and health anxiety. The ASI-3 is a short and cost-efficient measure which can be easily administered and so researchers and therapists can use the ASI-3 as a reliable and valid measure. The present study has several limitations. One of the limitations of this research was using the scale with a non-clinical sample of students and another is the convenience sampling method which may limit generalizability. We also did not have an adequate number of participants in subgroups (135 women and 85 men) to examine measurement invariance across genders. It is therefore necessary to examine the psychometric properties of the ASI-3, especially its factor structure, in the clinical community with clinically elevated levels of mood and anxiety disorders. Future studies are needed to establish invariance of the ASI-3 across genders with larger sample sizes. An extension of the present study is highly recommended to confirm the ASI-3 as an appropriate assessment measure in clinical psychology research and practice.

\section{Disclosure}

No conflicts of interest declared concerning the publication of this article.

\section{References}

1. Reiss S, McNally RJ. The expectancy model of fear. In: Reiss S, Bootzin RR, editors. Theoretical issue in behavior therapy. San Diego: Academic Press; 1985. p. 107-21.

2. Reiss S. Expectancy model of fear, anxiety, and panic. Clin Psychol Rev. 1991;11:141-53.

3. Taylor S, Cox BJ. An expanded Anxiety Sensitivity Index: evidence for a hierarchic structure in a clinical sample. J Anxiety Disord. 1998;12:463-83.

4. McNally RJ. Anxiety sensitivity and panic disorder. Biol Psychiatry. 2002;52:938-46.

5. Armstrong KA, Khawaja NG, Oei TP. Confirmatory factor analysis and psychometric properties of the Anxiety Sensitivity IndexRevised in clinical and normative populations. Eur J Psychol Assess. 2006;22:116-25.

6. Schmidt NB, Eggleston AM, Woolaway-Bickel K, Fitzpatrick KK, Vasey MW, Richey JA. Anxiety Sensitivity Amelioration Training (ASAT): A longitudinal primary prevention program targeting cognitive vulnerability. J Anxiety Disord. 2007;21:302-19.

7. Taylor S, Rabian B, Fedoroff I. Anxiety sensitivity: Progress, prospects, and challenges. In: Taylor S. Anxiety sensitivity: theory, research, and treatment of the fear of anxiety. London: Lawrence Erlbaum Associates; 1999. p. 339-55.

8. Olatunji BO, Wolitzky-Taylor KB. Anxiety sensitivity and the anxiety disorders: a meta-analytic review and synthesis. Behav Dev Bull. 2009;135:974-99.
9. Schmidt NB, Lerew DR, Jackson RJ. Prospective evaluation of anxiety sensitivity in the pathogenesis of panic: Replication and extension. J Abnorm Psychol. 1999;108:532-7.

10. Capron DW, Cougle JR, Ribeiro JD, Joiner TE, Schmidt NB. An interactive model of anxiety sensitivity relevant to suicide attempt history and future suicidal ideation. Psychiatry Res. 2012;46:17480.

11. Schmidt NB, Buckner JD, Keough ME. Anxiety sensitivity as a prospective predictor of alcohol use disorders. Behav Modif. 2007:31:202-19.

12. Deacon BJ, Valentiner DP. Dimensions of anxiety sensitivity and their relationship to nonclinical panic. J Psychopathol Behav Assess. 2001;23:25-33.

13. Ebesutani C, McLeish AC, Luberto CM, Young J, Maack DJ. A bifactor model of anxiety sensitivity: analysis of the Anxiety Sensitivity Index-3. J Psychopathol Behav Assess. 2014;36:45264.

14. Taylor S, Koch WJ, Woody S, McLean P. Anxiety sensitivity and depression: how are they related? J Abnorm Psychol. 1996;105:474-9

15. Kemper CJ, Ziegler M, Taylor S. Überprüfung der psychometrischen Qualität der deutschen Version des Angstsensitivitätsindex-3. Diagnostica. 2009;55:223-33.

16. Taylor S, Zvolensky MJ, Cox BJ, Deacon B, Heimberg RG, Ledley $D R$, et al. Robust dimensions of anxiety sensitivity: development and initial validation of the Anxiety Sensitivity Index-3. Psychol Assess. 2007;19:176-88.

17. Wheaton MG, Deacon BJ, McGrath PB, Berman NC, Abramowitz JS. Dimensions of anxiety sensitivity in the anxiety disorders: evaluation of the ASI-3. J Anxiety Disord. 2012;26:401-8.

18. Sandin B, Valiente RM, Chorot P, Germán MAS. ASI-3: nueva escala para la evaluación de la sensibilidad a la ansiedad. Rev Psicopatol Psicol Clin. 2007;12:91-104.

19. Escocard MRPG, Fioravanti-Bastos ACM, Landeira-Fernandez J. Anxiety sensitivity factor structure among brazilian patients with anxiety disorders. J Psychopathol Behav Assess. 2009;31:24655.

20. Mantar A, Yemez B, Alkin T. The validity and reliability of the Turkish version of the Anxiety Sensivity Index-3. Turk Psikiyatri Derg. 2010; 21:225-34.

21. Lim YJ, Kim JH. Korean Anxiety Sensitivity Index-3: its factor structure, reliability, and validity in non-clinical samples. Psychiatry Investig. 2012;9:45-53.

22. Kemper CJ, Lutz J, Bähr T, Rüddel H, Hock M. Construct validity of the Anxiety Sensitivity Index-3 in clinical samples. Assessment. 2012;19:89-100.

23. Farris SG, DiBello AM, Allan NP, Hogan J, Schmidt NB, Zvolensky MJ. Evaluation of the Anxiety Sensitivity Index-3 among treatment-seeking smokers. Psychol Assess. 2015;27:1123-8.

24. Ghisi M, Bottesi G, Altoè G, Razzetti E, Melli G, Sica C. Factor structure and psychometric properties of the Anxiety Sensitivity Index-3 in an Italian community sample. Front Psychol. 2016;7:113.

25. Osman A, Gutierrez PM, Smith K, Fang Q, Lozano G, Devine A. The Anxiety Sensitivity Index-3: analyses of dimensions, reliability estimates, and correlates in nonclinical samples. J Pers Assess. 2010;92:45-52.

26. Shah R, Goldstein SM. Use of structural equation modeling in operations management research: looking back and forward. Oper Man. 2006;24:148-69.

27. Kline RB. Principles and practice of structural equation modeling. New York: Guilford; 2015.

28. Pilowsky I. Dimensions of hypochondriasis. $\mathrm{Br} \mathrm{J}$ Psychiatry. 1967; 113:89-93.

29. HinzA, RiefW,BrählerE. Hypochondriein derAllgemeinbevölkerung: Teststatistische Prüfung und Normierung des Whiteley-Index. Diagnostica. 2003;49:34-42.

30. Welch PG, Carleton RN, Asmundson GJ. Measuring health anxiety: moving past the dichotomous response option of the original Whiteley Index. J Anxiety Disord. 2009;23:1002-7.

31. Barsky AJ, Cleary PD, Wyshak G, Spitzer RL, Williams JB, Klerman GL. A structured diagnostic interview for hypochondriasis: a proposed criterion standard. J Nerv Ment Dis. 1992;180:20-7.

32. Hiller W, Rief W, Fichter M. Dimensional and categorical approaches to hypochondriasis. Psychol Med. 2002;32:707-18.

33. Carleton RN, Norton MPJ, Asmundson GJ. Fearing the unknown: a short version of the Intolerance of Uncertainty Scale. J Anxiety Disord. 2007;21:105-17. 
34. Buhr K, Dugas MJ. The intolerance of uncertainty scale: psychometric properties of the English version. Behav Res Ther. 2002;40:931-45.

35. Besharat MA, Mirjalili RS, Ehsan HB. The mediating role of metacognitive beliefs and cognitive emotion regulation deficit on the relationship between cognitive perfectionism and worry in generalized anxiety disorder. J Fund Ment Health. 2015;17:115-22.

36. McCrae RR, Costa Jr PT. A contemplated revision of the NEO FiveFactor Inventory. Pers Individ Dif. 2004;36:587-96.

37. Mirzaei A, Nikbakhsh R, Sharififar F. The relationship between personality traits and sport performance. Eur J Exp Bio. 2013;3:439-42.

38. Anisi J, Majdiyan M, Joshanloo M, Ghoharikamel Z. Validity and reliability of NEO Five-Factor Inventory (NEO-FFI) on university students. Int J Beh Sci. 2011;5:351-5.

39. Bond FW, Hayes SC, Baer RA, Carpenter KM, Guenole N, Orcutt $\mathrm{HK}$, et al. Preliminary psychometric properties of the Acceptance and Action Questionnaire-II: A revised measure of psychological inflexibility and experiential avoidance. Behav Ther. 2011;42:67688.

40. Abasi E, Fti L, Molodi R, Zarabi H. Psychometric properties of Persian version of Acceptance and Action Questionnaire-II. Iran J Psychiatry Behav Sci. 2013;3:65-80.

41. Guillemin F, Bombardier C, Beaton D. Cross-cultural adaptation of health-related quality of life measures: literature review and proposed guidelines. Clin Epidemiol. 1993;46:1417-32.

42. Gjersing L, Caplehorn J.R, and Clausen T. Cross-cultural adaptation of research instruments: language, setting, time and statistical considerations. BMC Med Res Methodol. 2010;10:13.

43. Hayes SC. Content, context, and the types of psychological acceptance. In: Hayes SC, Jacobson NS, Follette VM, Dougher $\mathrm{MJ}$, editors. Acceptance and change: content and context in psychotherapy. Oakland: Context Press; 1994. p. 13-32.

44. Melli G, Carraresi C, Poli A, Bailey RJP. The role of metacognitive beliefs in health anxiety. Pers Individ Dif. 2016;89:80-5.

45. Norr AM, Albanese BJ, Oglesby ME, Allan NP, Schmidt NB. Anxiety sensitivity and intolerance of uncertainty as potential risk factors for cyberchondria. J Affect Disord. 2015;174:64-9.

46. MacCallum RC, Browne MW, Sugawara HM. Power analysis and determination of sample size for covariance structure modeling. Psychol Methods. 1996;1:130.

47. Petrocchi N, Tenore K, Couyoumdjian A, Gragnani A. The Anxiety Sensitivity Index-3: factor structure and psychometric properties in Italian clinical and non-clinical samples. Appl Psychol Bull. 2014;269:53-64.

48. Allan NP, Capron DW, Raines AM, Schmidt NB. Unique relations among anxiety sensitivity factors and anxiety, depression, and suicidal ideation. J Anxiety Disord. 2014;28:266-75.
49. Olthuis JV, Watt MC, Stewart SH. Anxiety Sensitivity Index (ASI-3) subscales predict unique variance in anxiety and depressive symptoms. J Anxiety Disord. 2014;28:115-24.

50. Rifkin LS, Beard C, Hsu KJ, Garner L, Björgvinsson T. Psychometric properties of the Anxiety Sensitivity Index-3 in an acute and heterogeneous treatment sample. J Anxiety Disord. 2015;36:99102.

51. Mohlman J, Zinbarg RE. The structure and correlates of anxiety sensitivity in older adults. Psychol Assess. 2000;12:440-6.

52. Naragon-Gainey K. Meta-analysis of the relations of anxiety sensitivity to the depressive and anxiety disorders. Psychol Bull. 2010;136:128-50.

53. Zinbarg RE, Barlow DH, Brown TA. Hierarchical structure and general factor saturation of the Anxiety Sensitivity Index: evidence and implications. Psychol Assess. 1997;9:277-84.

54. Wheaton MG, Berman NC, Franklin JC, Abramowitz JS. Health anxiety: latent structure and associations with anxiety-related psychological processes in a student sample. J Psychopathol Behav Assess. 2010;32:565-74.

55. Fergus TA, Bardeen JR. Anxiety sensitivity and intolerance of uncertainty: evidence of incremental specificity in relation to health anxiety. Pers Individ Dif. 2013;55:640-4.

56. O'Bryan EM, McLeish AC. An examination of the indirect effect of intolerance of uncertainty on health anxiety through anxiety sensitivity physical concerns. J Psychopathol Behav Assess. 2017;39:715-22.

57. Abramowitz JS, Braddock A. Psychological treatment of health anxiety and hypochondriasis: a biopsychosocial approach. Göttingen: Hogrefe; 2008. p. 13-40.

58. Esteve R, Ramírez-Maestre C, López-Martínez A. Experiential avoidance and anxiety sensitivity as dispositional variables and their relationship to the adjustment to chronic pain. Eur J Pain. 2012;16:718-26.

59. Kämpfe CK, Gloster AT, Wittchen H-U, Helbig-Lang S, Lang T, Gerlach AL, et al. Experiential avoidance and anxiety sensitivity in patients with panic disorder and agoraphobia: Do both constructs measure the same? Int J Clin Health Psychol. 2013;12:5-22.

\section{Correspondence:}

Mohsen Mohammadpour

Kermanshah University of Medical Sciences

Kermanshah, Iran

Tel.: 0989185645752

E-mail: mohammadpour5711@gmail.com 